\title{
A front-end biopotential measurement module
}

\author{
Chun-Yu Chen, Yue-Der Lin, Fok-Ching Chong and * Shing-Ming Sung \\ Department of Electrical Engineering, National Taiwan University \\ *Department of Neurology, Taipei Municipal Jen-Ai Hospital
}

\begin{abstract}
A front-end biopotential measurement module which could be applied to the measurement of surface biopotential is presented in this study. This module,mainly composed of an isolation amplifier (iso. amp) and an active electrode, has the advantages of low cost, easy implementation and no need of skin preparation and paste. The user could also easily modify this module to their specific applications. The design of the measurement module and its characteristics are also demonstrated.
\end{abstract}

Keywords : biopotential, isolation amplifier (iso amp) , active electrode

\section{INTRODUCTION}

In clinical diagnosis, the recording of surface biopotential is important.The usual method of measuring surface biopotential is the gluing of nonpolarizable $\mathrm{Ag} / \mathrm{AgCl}$ electrodes to the desired positions. This would waste time as the technicians should prepare the surface of skin, degrease the recording area by cleaning it with alcohol, then apply the conducting paste to $\mathrm{Ag} / \mathrm{AgCl}$ electrodes with collodion or hold them in place with nubber straps. These skin preparations could cause further drawbacks such as a)irritation of the patient's skin and b)potential shift or signal-transmit error due to long time measurement.c) environmental noise is easily induced by the lead wire that links the electrode and the amplifier[1]. For safety sake, galvanic isolation of the patient during bioelectric measurement is necessary. An iso amp is usually needed to meet this requirement, yet the price of a commercial product(ex: $A D 210)$ is expensive and this economical problem would be enhanced in multichannel recording, such as electroencephalogram(EEG).

The goals of this study is to overcome the drawbacks described above. The active electrode using an FET-input op amp instead of the $\mathrm{Ag} / \mathrm{AgCl}$ electrode. No more skin preparations are required and the conductive paste becomes unnecessary as the input impedance of the active electrode is high enough compared with the skin impedance, and the noise induced by the lead wire would be reduced as the output impedance of the active electrode is very low. The active electrodes were connected to the designed iso. amp, thus the biopotential measurement module was constructed. The user could only add post-stage amplifiers and filters to this module to fit their specific surface biopotential application. This low-cost front-end measurement module is helpful especially in the laboratory as the design of measurement system is desired.

\section{METHODS AND MATERIALS :}

The structure and the electric circuit of the active electrode are demonstrated in Fig.1, which looks somewhat like the work of Nishimura et al.,\{2]. In order to have a very high input impedance and smail size, an FETinput op amp (AD820, Analog Devices, less than four US dollars) in surface mount package that connected as a voltage follower was adopted. The electrode material is stainless steel as its skin-to-electrode impedance is relatively less affected by the presence of perspiration[3].

The circuit of the isolated amplifier is shown in Fig.2. The overall gain of the iso amp is 50. The users could add post-stage amplifiers and filters according to the bioelectric event being concerned. The iso amp is composed of instrumentation amplifier, optoisolators, low-noise op amp and resistors. One feature of this iso amp is the adding of a matched optoisolator on the source side, the idea is drawn from the design criterion of Burr Brown ISO100 iso amp[4], to improve the linearity between LED input current and output collector current.

\section{RESULT :}

The features of the active electrode is listed on Table I. The requirements for the electrode of very high input impedance and very low output impedance are fulfilled. The 
specification of the designed iso. amp is shown on Table II.

\section{DISCUSSION :}

In this study, the design of a low-cost biopotential measurement module is demonstrated. The components of this module are all commercially available and low cost. This lowcost, easily implemented and small-size module is especially suitable for multichannel recording of surface biopotential in the laboratory. In addition. the users could serve their purpose of measuring different surface biopotential signals which have their specific voltage and frequency ranges easily only by adding amplifiers and filters. And it is also promising in clinical application as the shielding capability is improved

\section{REFERENCES}

[1] J.W.Clark, Jr., "The origin of biopotentials" in Medical Instrumentation Application and Design, Ed. by J.G.Webster, 2nd ed., 1992, pp.150-226, Houghton Mifflin, Boston-Toronto.

[2] S. Nishimura, Y.Tomita and T.Horiuchi, "Clinical application of an active electrode using an operation amplifier", IEEE Trans. Biomed. Eng., vol.39, no. 10. 1992, pp. 1096-1099.

[3] G.E.Bergey, R.D. Squires and W.C.Sipple, "Electrocardiogram recording with pasteless electrodes". IEEE Trans. Biomed.Eng., vol.18, no.3, 1971, pp. 206-211.

[4] W.H.Olson, "Electrical safety", in Medical Instrumentation-Application and Design, Ed. by J.G.Webster. 2nd ed., 1992, pp.751-792.

Fig.2 The circuit of the iso amp

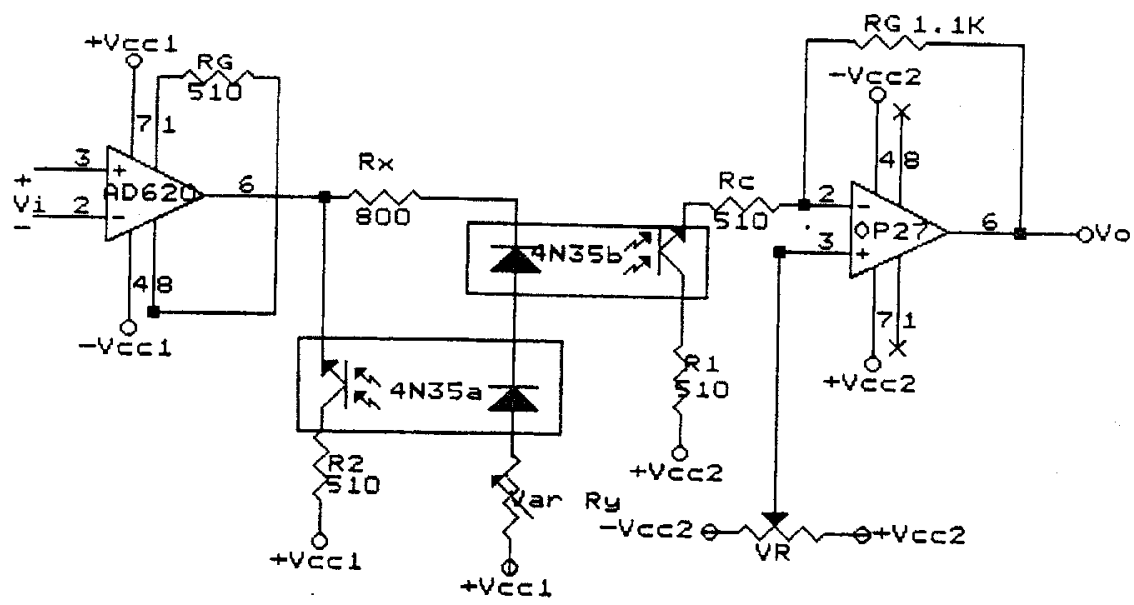

Fig. 1 The structure of the active electrode

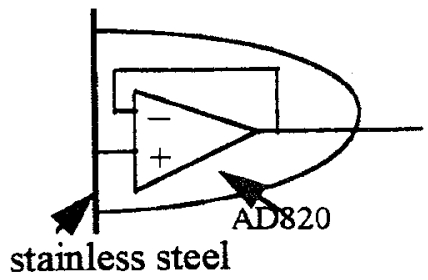

Table I

The specification of the active electrode

\begin{tabular}{|c|c|}
\hline & Active Electrode \\
\hline Bandwidth, $\mathrm{Hz}$ & $2 \mathrm{M} \mathrm{Hz}$ \\
\hline Gain(close loop) & 0.95 \\
\hline $\begin{array}{l}\text { Differential mode input } \\
\text { impedance } \Omega \text { at } 60 \mathrm{~Hz}\end{array}$ & $3 \times 10^{12}$ \\
\hline $\begin{array}{l}\text { Common mode input } \\
\text { impedance } \Omega \text { at } 60 \mathrm{~Hz}\end{array}$ & $3 \times 10^{12}$ \\
\hline CMRR at $60 \mathrm{~Hz}$ & $80 \mathrm{~dB}$ \\
\hline
\end{tabular}

Table II

The specification of the iso amp

\begin{tabular}{|c|c|c|}
\hline & $\mathrm{AD} 210$ & Iso. Amp \\
\hline $\begin{array}{l}\text { Equivalant input noise } \\
\text { voltage } n V \mathrm{rms}, 1 \mathrm{~K} \mathrm{~Hz}\end{array}$ & $10 \mathrm{nV} / \sqrt{H z}$ & $9 \mathrm{nV} / \sqrt{H z}$ \\
\hline $\begin{array}{l}\text { Equivalent input noise } \\
\text { current pA rms, } 1 \mathrm{~K} \mathrm{~Hz}\end{array}$ & $0.01 \mathrm{pA} / \sqrt{H z}$ & $100 f \mathrm{~A} \sqrt{H z}$ \\
\hline Bandwidth, $\mathrm{Hz}$ & $15 \mathrm{~K} \mathrm{~Hz}$ & $20 \mathrm{~K} \mathrm{~Hz}$ \\
\hline $\begin{array}{c}\text { Input bias cuerrent, } \\
\text { nA per input }\end{array}$ & 10 & 2.0 \\
\hline Gain & $1 \mathrm{~V} / \mathrm{V} \sim 100 \mathrm{~V} / \mathrm{V}$ & $50-100 \mathrm{~V} / \mathrm{V}$ \\
\hline $\begin{array}{l}\text { Differential mode input } \\
\text { impedance } \Omega \text { at } 60 \mathrm{~Hz}\end{array}$ & $10^{3} \mathrm{G}$ & $10 \mathrm{G} \Omega / / 2 \mathrm{pF}$ \\
\hline $\begin{array}{l}\text { Common mode input } \\
\text { impedance } \Omega \text { at } 60 \mathrm{~Hz}\end{array}$ & $5 \mathrm{G} \Omega / / 5 \mathrm{pF}$ & $10 G \Omega / / 2 \mathrm{pF}$ \\
\hline CMRR at $60 \mathrm{~Hz}$ & $120 \mathrm{~dB}$ & $36 \mathrm{~dB}$ \\
\hline $\begin{array}{l}\text { Power Comsumption } \\
\text { mW per channel }\end{array}$ & 150 & 593 \\
\hline Price & $>$ US\$60 & US\$10 \\
\hline
\end{tabular}

